\title{
Copper, Lead and Cadmium Loads and Behavior in Urban Stormwater Runoff in Curitiba, Brazil
}

\author{
Ellen C. Prestes, Vanessa E. dos Anjos, Fernando F. Sodré and Marco T. Grassi* \\ Departamento de Química, Universidade Federal do Paraná, CP 19081, 81531-990 Curitiba - PR, Brazil
}

\begin{abstract}
O objetivo deste trabalho foi avaliar a presença e o comportamento do $\mathrm{Cu}, \mathrm{Pb}$ e $\mathrm{Cd}$ em águas de drenagem urbana na cidade de Curitiba, no Brasil. As amostras foram coletadas durante 21 eventos de chuva em uma avenida de tráfego médio. As concentrações dos metais foram similares àquelas descritas na literatura, seguindo a ordem $\mathrm{Pb}>\mathrm{Cu}>>\mathrm{Cd}$. Uma estimativa da carga anual dos três metais para a Bacia do Rio Bacacheri, de $30 \mathrm{~km}^{2}$, revelou valores de 1.520 , 950 e $25 \mathrm{~kg}$ para $\mathrm{Pb}, \mathrm{Cu}$ e $\mathrm{Cd}$, respectivamente. O chumbo mostrou-se preferencialmente associado ao material particulado (82\%), seguido do cádmio $(66 \%)$ e do cobre $(48 \%)$. Na fração dissolvida ficou evidenciada uma relação dos metais com a matéria orgânica dissolvida, seguindo a ordem $\mathrm{Cu}>\mathrm{Pb}>\mathrm{Cd}$. As concentrações dos metais também variaram em função de fatores tais como o primeiro fluxo e o número de dias de estiagem que precedem um evento de chuva.
\end{abstract}

We investigate the presence and behavior of $\mathrm{Cu}, \mathrm{Pb}$, and $\mathrm{Cd}$ in runoff waters from a residential area located in the city of Curitiba, Brazil. Samples were collected in twenty-one stormwater events in an intermediate traffic way located in the Bacacheri watershed. Metal concentrations were similar to range values compiled worldwide and followed the order: $\mathrm{Pb}>\mathrm{Cu}>>\mathrm{Cd}$. Unit loads were estimated to the watershed, which cover an area of $30 \mathrm{~km}^{2}$, revealing values of 1520 , 950, $25 \mathrm{~kg}$ for $\mathrm{Pb}, \mathrm{Cu}$, and $\mathrm{Cd}$, respectively. Among the three metals, lead showed the greatest affinity for the suspended solids (82\%) followed by $\mathrm{Cd}(66 \%)$ and $\mathrm{Cu}(48 \%)$. Meanwhile, an association of the metals with the organic matter in the dissolved phase, following the order $\mathrm{Cu}>\mathrm{Pb}>\mathrm{Cd}$. Metal loads and behavior in urban runoff also depends on factors such as the first flush and the dry period preceding a storm event.

Keywords: heavy metal, urban stormwater runoff, pollution load, nonpoint source

\section{Introduction}

Nonpoint pollution resulting from urban stormwater runoff has been identified as one of the major causes of the deterioration of the quality of surface receiving waters. ${ }^{1-3}$ During stormwater events water runs on the surface washing away a variety of pollutants alongside the drainage area and reaches, intermittently, receiving water bodies. ${ }^{4,5}$ Additionally, in urban areas, impervious surfaces such as roads, bridges, parking lots, and buildings do not allow the slow percolation of the water into the ground. In this case, the water remains above the surface, accumulating and running off in large amounts. ${ }^{6,7}$

Many previous studies revealed that nonpoint emissions remain the largest source of water quality problems in developed countries. Nowadays, it is the main

*e-mail: mtgrassi@quimica.ufpr.br reason that approximately $40 \%$ of rivers, lakes, and estuaries located in the United States are not clean enough to meet basic uses such as fishing or swimming. ${ }^{8}$ In Brazil, as well as in many developing countries, the identification and monitoring of nonpoint sources still represent a great challenge. In fact, this issue has not been properly addressed and the pollutant content of urban surface waters has been most exclusively associated to point emissions, especially in heavily urbanized areas. Very few reports focus on the importance of nonpoint emissions and the National Water Resources Policy does not tackle nonpoint pollution sources. However, it has been recently shown that variations in urban runoff quality are greater than variations in raw and treated sewage wastewaters. ${ }^{5}$ Moreover, in a previous work ${ }^{9}$ we demonstrated that both point and nonpoint emissions are significant contributors to copper loadings in urban surface waters in the city Curitiba, Brazil. Using the Principal Component Analysis 
technique based on aquatic parameters we revealed that during the lower precipitation period, point sources such as raw sewage play a major role on copper loads whilst at the rainy season, it became clear that there is an influence of nonpoint sources on copper discharges to rivers located in Curitiba's Metropolitan Region.

Metals are the best understood toxic pollutants in urban runoff. Many investigations report significant levels of heavy metals in urban and in highway runoffs. ${ }^{10-12}$ Among a variety of metals present in stormwater, copper, lead, and cadmium are the most hazardous ones. ${ }^{13}$ The concentration of copper an lead range between 5 to 200 $\mu \mathrm{g} \mathrm{L}^{-1}$ whilst cadmium levels are not superior to $12 \mu \mathrm{g}$ $\mathrm{L}^{-1} \cdot{ }^{14}$ The primary source of many metals in urban runoff is vehicle traffic. Concentrations of copper, lead, and cadmium appear to be directly correlated to traffic intensity on surfaces such as highways, streets, and parking lots. ${ }^{15,16}$ Runoff originated in roofs is also a significant source of copper, and cadmium. ${ }^{13,17}$

Recent studies on heavy metal pollution in urban waters have found that metal transport and behavior is closely related to the partitioning of the metal between the dissolved and particulate phases, where suspended solids play an important role in the transport processes. ${ }^{18,19}$ Sansalone and Buchberger ${ }^{20}$ found that lead in urban roadway stormwater was mostly associated with suspended solids during storm events whereas $\mathrm{Cd}$ and $\mathrm{Cu}$ were mainly in the dissolved fraction. The behavior of many metals in urban runoff also depends on the metalbinding properties as well as the characteristics of both particulate and dissolved materials. ${ }^{21}$ Marsalek and Marsalek $^{22}$ showed that lead, copper, and zinc are strongly associated to smaller particles in sediments from a stormwater management pond. Sartor and co-workers ${ }^{23,24}$ found that the smallest fraction of particles contained 5.9\% of the total mass, but over $50 \%$ of the heavy metals content.

Solid materials constitute the largest volume of pollutant loads to receiving waters in urban areas. ${ }^{25}$ Newell et $a l .{ }^{26}$ estimated that under average conditions, over $40 \%$ of the particulate solids entering the Galveston Bay in Texas (USA) originated from urban stormwater runoff from the Houston Metropolitan Area. A recent study carried out in Austin, also in Texas, revealed that total suspended solids as well as heavy metal loads in urban runoff were closely related to aspects such as drainage area, surrounding land use, and daily traffic flow. ${ }^{15}$ This last study reported annual loads for total suspended solids varying from 101 to $1306 \mathrm{~kg} \mathrm{ha}^{-1}$. Lee and Bang ${ }^{12}$ carried out an urban stormwater runoff characterization in nine watersheds in the cities of Taejon and Chongju in South Korea and found annual average mass loadings of suspended solids of $197 \mathrm{~kg} \mathrm{ha}^{-1}$ in industrial areas and more than $1800 \mathrm{~kg} \mathrm{ha}^{-1}$ in residential catchments. Pollutant concentrations and loads in urban runoff also depend on topography, vegetal covering, streets and highways sweeping, specific materials and components employed within the drainage area, as well as hydrometeorological effects such as rainfall intensity and extent. 14,27,28 $^{2}$

A particular characteristic in stormwater events is the higher concentration of pollutants at the beginning of a runoff event, a phenomenon commonly referred to as the first flush. ${ }^{29}$ Barbosa and Hvitved-Jacobsen ${ }^{30}$ observed that the first $50 \%$ of the runoff volume for each monitored rainfall event typically transported between 61 to $69 \%$ of the total suspended solids, zinc, copper, and lead loads. Strong correlations between runoff intensity and dissolved organic carbon as well as total suspended solids concentrations were also recently reported. ${ }^{12}$

Owing to the lack of knowledge on the importance of urban runoff in developing countries, this study was instigated. Consequently, the principal aim of the study was to evaluate the presence and the behavior of lead, copper, and cadmium as well as the main characteristics of urban runoff in the city of Curitiba, Brazil.

\section{Experimental}

\section{Sampling site}

The sampling site, selected to represent an urban environment and to allow the assessment of the metal loads and behavior in urban runoff, was located in the José Gulin Av., an intermediate-traffic way on the northeast edge of the city of Curitiba (Figure 1). The land use around the sampling site is mostly residential and undeveloped. The

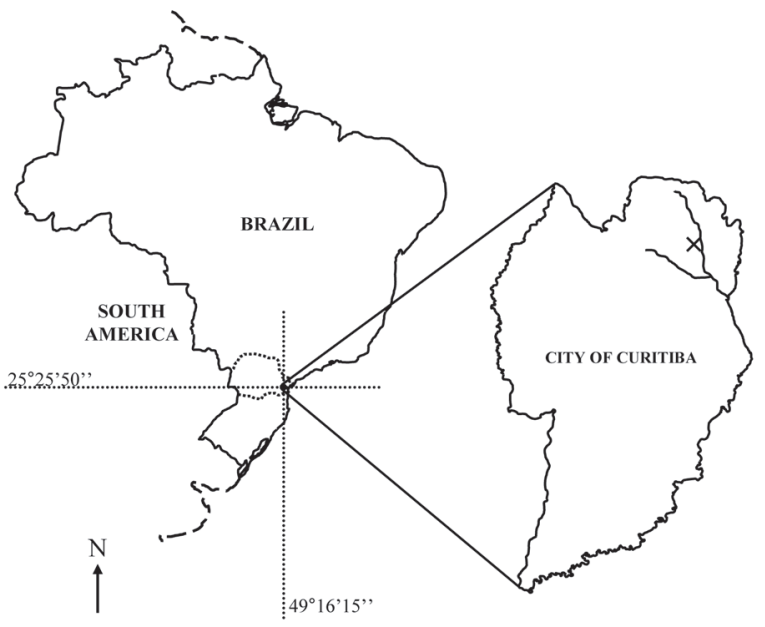

Figure 1. Location of the sampling site in the Bacacheri watershed, Curitiba, Brazil. The X symbol indicates the sampling point at the José Gulin Avenue. 
average traffic flow rate in this avenue is approximately 9,000 vehicles per day in both traffic lanes and the pavement consisted of an impervious asphalt surface. The experimental section, which is $100 \%$ asphalt-paved, drains 1,300 $\mathrm{m}^{2}$ of the avenue. Runoff samples were collected directly from the lateral gutter in twenty-one storm events from September 2002 to March 2004. The José Gulin Avenue is located nearby the Bacacheri River which receives runoff from the experimental sampling section. The Bacacheri watershed covers an area of approximately $30 \mathrm{~km}^{2}$.

\section{Sample collection and preparation}

Samples were collected by hand during runoff events directly on the pathway outflow using pre-washed polyethylene bottles. The collection was based on the volume of runoff flowing past the sampling point and the samples were taken immediately when runoff was high enough to be captured. The samples were stored at $4{ }^{\circ} \mathrm{C}$ until the analyses. In the laboratory, an aliquot of each sample was immediately acidified with purified $\mathrm{HCl}$ to give a final concentration of approximately $0.01 \mathrm{~mol}$ $\mathrm{L}^{-1} \cdot{ }^{31}$ To distinguish between total recoverable and dissolved metal concentrations another portion was filtered under vacuum through a $0.45 \mu \mathrm{m}$ pore size cellulose acetate membrane (Schleicher and Schuell) into an acidwashed polyethylene bottle. The filtered fraction was also acidified with purified $\mathrm{HCl}$. Both filtered and unfiltered samples were submitted to a microwave-assisted photochemical digestion ${ }^{32}$ in order to release the particulate metal and destroy any organic matter that could interfere with metal determinations. Total recoverable metal (TRM) concentrations were determined in unfiltered samples whereas total dissolved metal (TDM) were obtained from the filtered ones.

To minimize sample contamination during the steps aforementioned all procedures were performed according to clean techniques. ${ }^{31}$ All labware was maintained in a $10 \%$ detergent bath for a week. After this period the labware was removed and rinsed thoroughly with distilled water, and was placed into a second bath containing a $10 \% \mathrm{HNO}_{3}$ solution for at least $24 \mathrm{~h}$. Finally, all the material was rinsed copiously with Milli-Q type water (Milli-Q Academic, Millipore). Prior to the sampling, the sampling bottles were filled with an $\mathrm{HCl}$ solution. Hydrochloric acid was purified in the laboratory by isothermal distillation. ${ }^{33}$

\section{Analysis}

The determination of copper, lead, and cadmium in runoff samples was performed via Differential Pulse
Anodic Stripping Voltammetry (DPASV), which allows the simultaneous determination of the three metals. Measurements were carried out in an EG\&G Princeton Applied Research 394 Electrochemical Trace Analyzer coupled with an EG\&G PAR 303A Static Mercury Drop Electrode. Total metal concentrations were measured by the method of standard additions. The instrument setup for DPASV determinations was $10 \mathrm{~min}$ purge with purified $\mathrm{N}_{2}, 10$ min electrodeposition at $-1.2 \mathrm{~V}$ vs. $\mathrm{Ag} / \mathrm{AgCl}$ followed by the anodic scan from -0.9 to $+0.1 \mathrm{~V}$ at $4 \mathrm{mV}$ $\mathrm{s}^{-1}$, with $50 \mathrm{mV}$ pulse height.

Total suspended solids (TSS), dissolved organic carbon (DOC), and $\mathrm{pH}$, were determined in all samples. The latter was measured as soon as the samples were brought to the laboratory. TSS and DOC levels were assessed according to the Standard Methods for the Examination of Water and Wastewater. ${ }^{34}$ Daily precipitation data were kindly provided by Instituto Tecnológico Simepar.

\section{Results and Discussion}

Figure 2 presents box-whisker graphs of some data obtained for the samples of drainage water collected during the 21 storm events.

Figure 2 shows that the concentrations of all parameters vary greatly from one rainfall event to another, with variations factors of 3 for $\mathrm{pH}, 11-12$ for DOC concentrations, 160 for TSS levels, and more than 350 for the metal concentrations. Despite the great variability of all parameters listed in Figure 2, the range and mean values were similar to those reported in previous works compiled worldwide. The $\mathrm{pH}$ mean and median values obtained in our work were in the range between 6.5 and 7.0 and agree to the values reported by Davis et al..${ }^{14}$ Barbosa and Hvited-Jacobsen, ${ }^{30}$ and Legret and Pagotto. ${ }^{35}$ DOC mean and median concentration were 8.8 and $6.7 \mathrm{mg} \mathrm{L}^{-1}$ and also agree with values observed in highway runoffs. ${ }^{11}$ The TSS concentrations showed the greater variability during the sampling period with mean and median values of 106 and $75.3 \mathrm{mg} \mathrm{L}^{-1}$, respectively. These results are in agreement with TSS levels from residential areas of Northern European countries. ${ }^{3}$ Sansalone and Buchberger ${ }^{20}$ reported that TSS levels and characteristics are strongly dependent on paved surfaces that transport a wide gradation of solids ranging from sub-micron particles to gravel size aggregates. According to Taebi and Droste ${ }^{5}$ the concentration of particles in stormwater runoffs can be greater than a discharge from a secondary plant effluent. Depending on the rainfall intensity, urban runoff can contain more solids than raw sewage effluents. ${ }^{5}$ From 


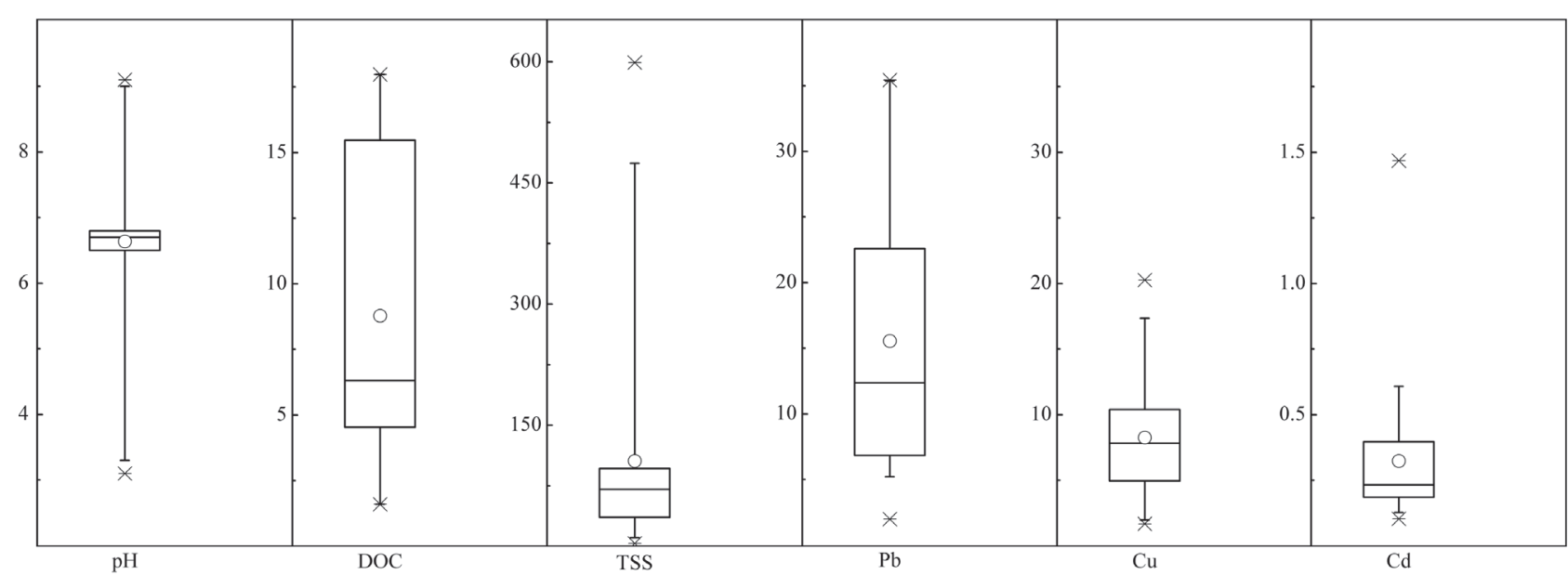

Figure 2. pH, DOC, TSS, and total recoverable metal concentrations in urban runoff samples collected in twenty-one stormwater events from September 2002 to March 2004. The large box represents the $25^{\text {th }}$ percentile, median, and $75^{\text {th }}$ percentile; error bars indicate the $5^{\text {th }}$ and $95^{\text {th }}$ percentiles; whiskers represent the $1^{\text {st }}$ and $99^{\text {th }}$ percentiles; dashes symbolize the minimum and maximum values; open circles represent the arithmetic mean. DOC and TSS are given in $\mathrm{mg} \mathrm{L}^{-1} ; \mathrm{Pb}, \mathrm{Cu}$, and $\mathrm{Cd}$ concentrations are given in $\mu \mathrm{g} \mathrm{L}^{-1}$.

Figure 2 we were able to observe that the total recoverable concentrations of lead, copper, and cadmium follow the order $\mathrm{Pb}>\mathrm{Cu}>>\mathrm{Cd}$. Lead and copper mean concentration were in the same magnitude with values of 15 and $8.3 \mu \mathrm{g} \mathrm{L}^{-1}$, respectively. On the other hand, cadmium concentrations were significantly lower ranging from 0.10 to $1.5 \mu \mathrm{g} \mathrm{L}^{-1}$ with a mean concentration of $0.32 \mu \mathrm{g} \mathrm{L}^{-1}$. Mitchell ${ }^{3}$ reports higher mean concentrations of lead $\left(60.6 \mu \mathrm{g} \mathrm{L}^{-1}\right)$, copper $\left(27.9 \mu \mathrm{g} \mathrm{L}^{-1}\right)$, and cadmium $\left(2.2 \mu \mathrm{g} \mathrm{L}^{-1}\right)$ in urban runoff data compiled from several countries. Davis and co-workers ${ }^{14}$ estimated the loads of lead, copper, cadmium, and zinc in urban runoff from specific sources and reported ranging concentrations similar to those determined in our work. According to the authors the primary source of lead and copper was the deterioration of vehicles brakes and tires, as well as the atmospheric deposition. Runoff from roofs is also an important source of copper, lead, and cadmium. ${ }^{13,17}$ The presence of cadmium in urban stormwater runoff was also reported to be directly associated with dry deposition. ${ }^{14}$

For many types of surface water bodies pollutant load is a more relevant indicator of potential effects on water quality than mean concentrations are. For the Bacacheri watershed the pollutant load was estimated by the product between the volume of runoff from the experimental section of the sampling site and the concentration of a specific constituent. ${ }^{15,35}$ Due to logistic difficulties we were not able to collect samples in all rainfall events that took place during the sampling period. Therefore, annual pollutant loads for the drainage area under study were calculated according to the equation described by Legret and Pagotto ${ }^{35}$ and shown as

$L=\frac{P}{\sum P_{\mathrm{e}}} \frac{V}{\sum V_{\mathrm{e}}} \sum L_{\mathrm{e}}$

where $L$ is the annual pollutant load $\left(\mathrm{kg} \mathrm{m}^{-2}\right), P$ represents the annual precipitation $(1129 \mathrm{~mm}), P_{\mathrm{e}}$ is the precipitation during each storm event $(\mathrm{mm}), V$ is the annual runoff volume $\left(\mathrm{m}^{3}\right), V_{\mathrm{e}}$ is the runoff volume computed for each storm event (mm), and $L_{\mathrm{e}}$ means the pollutant load for each individual storm event. The two first terms in equation (1) represent a correction factor that adjusts for storms where no runoff was collected. The pollutant load for each storm event $\left(L_{\mathrm{e}}\right)$ was calculated as

$L_{\mathrm{e}}=c V_{\mathrm{e}}$

where $c$ represents the mean concentration of the pollutant constituent $\left(\mathrm{mg} \mathrm{m}^{-3}\right)$ for each runoff sample. $V_{\mathrm{e}}$ was obtained as

$V_{\mathrm{e}}=P_{\mathrm{e}} A K_{\mathrm{i}}$

where $A$ is the measured drainage area $\left(\mathrm{m}^{2}\right)$ and $K_{\mathrm{i}}$ represents an impermeability coefficient (0.60) of the studied area. ${ }^{7}$ Figure 3 presents the pollutant loading estimates obtained for $\mathrm{Cu}, \mathrm{Pb}$ and $\mathrm{Cd}$.

The annual loads shown in Figure 3 are presented in terms of the mass of pollutant per hectare and follow the same pattern as the mean concentration. Commonly, literature data for pollutant loadings from urban surfaces are scattered and present great variation. Barret et al. ${ }^{15}$ 


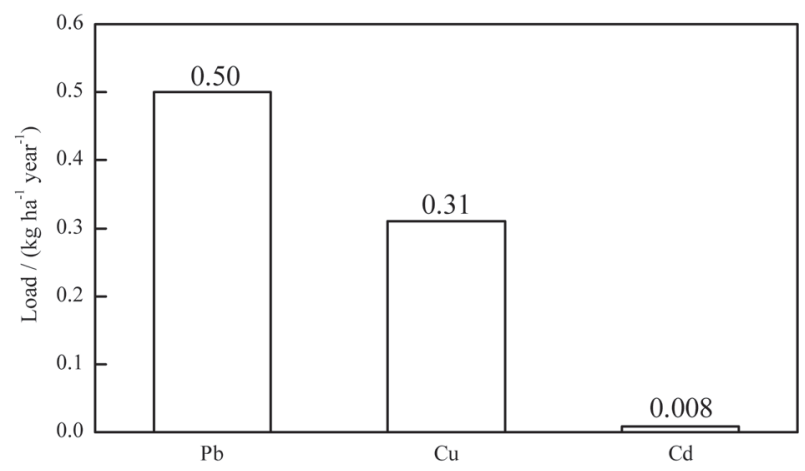

Figure 3. Lead, copper, and cadmium annual loadings, in $\mathrm{kg} \mathrm{ha}^{-1}$, from urban stormwater runoff, to the Bacacheri watershed.

evaluated lead and copper loads from three different sites in Austin (Texas-USA) and reported annual loads of 0.47 and $0.23 \mathrm{~kg} \mathrm{ha}^{-1}$, respectively, in a high-traffic site located in a residential/commercial area. Legret and Pagotto ${ }^{35}$ found pollutant loads of $0.43,0.27$, and $0.010 \mathrm{~kg} \mathrm{ha}^{-1}$ for $\mathrm{Pb}, \mathrm{Cu}$, and $\mathrm{Cd}$, respectively, in runoff waters from a major rural highway in Loire-Atlantique (France). The aforementioned studies, as well as this work, present similar pollutant loads, although obtained in different site locations concerning aspects such as traffic, land use, climate, etc. In fact, the similarities may be explained both by anthropogenic aspects and disparities in the stock of pollutants existing on the streets and highways. ${ }^{36}$ The differences in runoff pollutant concentrations and loads are usually broad due to the complexity of the contaminant sources. Nevertheless, unit metal loads from stormwater runoffs were also estimated for Bacacheri watershed. The results, expressed in terms of mass, indicate annual loads of 1520,950 , and $25 \mathrm{~kg}$ for $\mathrm{Pb}, \mathrm{Cu}$, and $\mathrm{Cd}$, respectively. These results demonstrate the relevance of nonpoint pollution to the quality of natural waters.

Hydrometeorological aspects are known as an important issue when taking into account pollutant loads and concentrations. High pollutant loads may occur when a long dry period precedes the storm. In fact, during the sampling period we were able to determine that a 10days period preceding a storm event yielded a 3 to 5 -fold increase in metal concentrations and more than 30 -fold increase in TSS levels in urban runoff waters. Also, the variation in the drainage water quality during a single stormwater event is a significant characteristic reported in the literature. ${ }^{12,15,16}$ Heavy metal concentrations, for instance, can vary during the drainage of waters from impervious surfaces due to a phenomenon known as the first flush. ${ }^{29}$ Figure 4 shows the first flush evaluation performed for the dissolved and particulate metal concentrations as well as for the TSS concentrations during a rainfall that took place on January 24th, 2004.
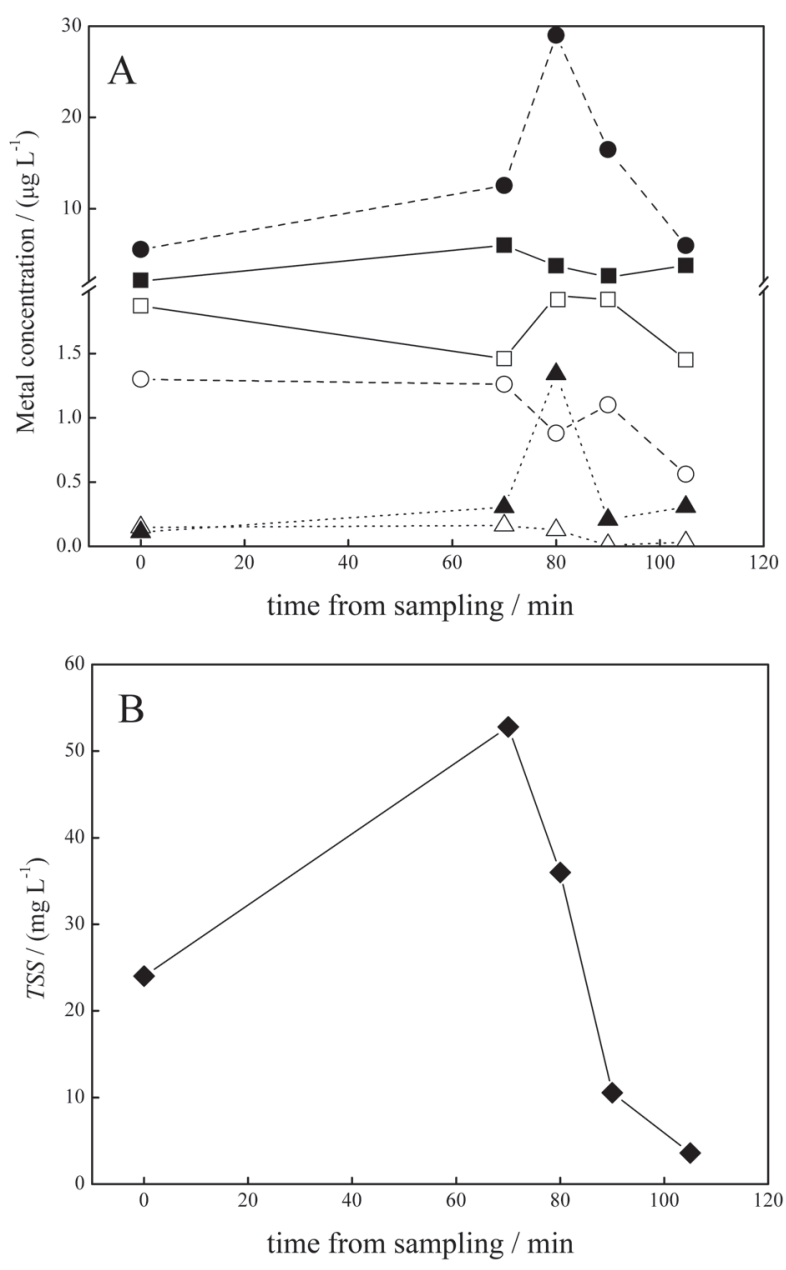

Figure 4. Variation of (A) dissolved and particulate metal concentrations and (B) total suspended solids concentration during the first flush. $\mathrm{Cu}$, $\mathrm{Pb}$, and $\mathrm{Cd}$ are represented by squares, circles, and up triangles, respectively. Open symbols indicate the dissolved fraction whereas closed symbols correspond to the particulate-bound metal.

In the rainfall event shown in Figure 4, time was initialized to zero as soon as runoff was sufficiently high to be sampled. After the first sample was taken, rainfall intensity decreased to a light rain and runoff could not be captured. As the rainfall intensity became greater subsequent runoff samples were collected at 70, 80, 90, and $105 \mathrm{~min}$. Figure 4 depicts that the particulate fraction of $\mathrm{Pb}$ and $\mathrm{Cd}$ as well as TSS concentrations exhibit a pronounced first flush-type behavior whereas particulate $\mathrm{Cu}$ does not. Opposed to that, only dissolved copper exhibits a strong first flush behavior. This overall behavior represents an important information concerning managing practices of urban drainage water and is quite often a strong motive to justify that the first drainage volumes are captured and treated. ${ }^{15}$

It is important to point out that usually the behavior portrayed in Figure 4 is not only time-dependent. As a 
matter of fact there are other factors such as the water flow that are believed to rule the first flush phenomenon. ${ }^{15}$ Lee and Bang ${ }^{12}$ investigated the characteristics of pollutants overflow on storm events and showed that the pollutant concentration peak occurs nearly after or before the flow peak depending on the watershed area and impermeability. Although the water flow was not determined during the 24 January rainfall, it is possible to observe that there is a good relationship between TSS levels and particulate $\mathrm{Pb}$ and $\mathrm{Cd}$ whereas $\mathrm{Cu}$ appears to be preferentially in the dissolved phase. In fact, the distribution of the three metals between the solid and dissolved phases was determined for all samples collected in this study. Figure 5 shows the average percentage concentration of the metals associated to the solid phase.

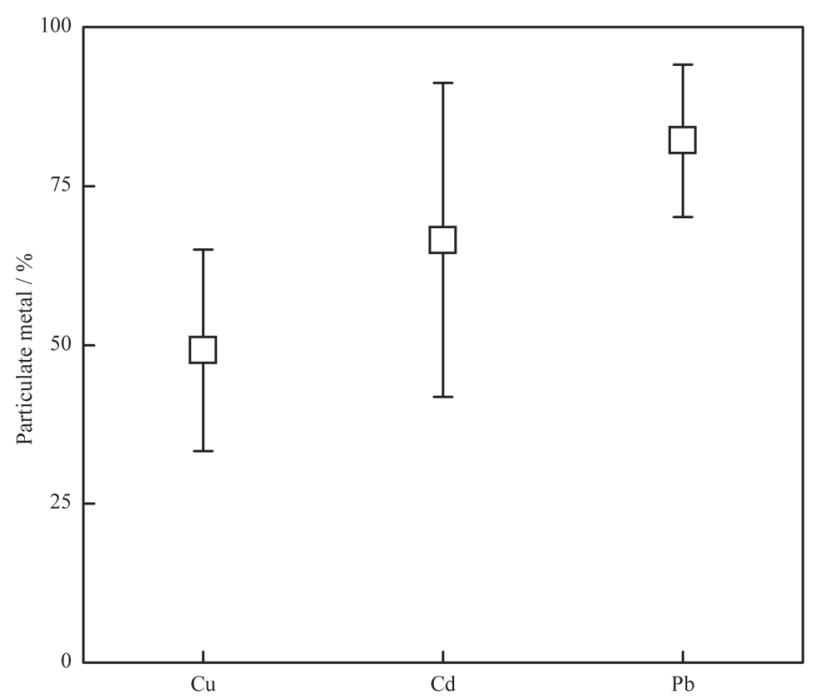

Figure 5. Relative concentrations of particulate metals in urban stormwater runoff.

Figure 5 shows that $\mathrm{Pb}$ exhibited the highest affinity to the particulate matter, about $82 \%$, followed by $\mathrm{Cd}(66 \%)$ and $\mathrm{Cu}(48 \%)$. Sansalone and Buchberger ${ }^{20,29}$ developed a study involving the characterization and metal distributions in urban highway stormwater and also found that $\mathrm{Pb}$ was mostly associated with the particles. This particular behavior was recently applied to predict $\mathrm{Pb}$ loads in urban drainage water via a model built with the TSS loads from runoff events. ${ }^{18}$ In opposition to the behavior described for lead, copper has been commonly found in the dissolved fraction. ${ }^{20}$ The behavior of cadmium obtained in this study does not agree with the literature, where $\mathrm{Cd}$ has been commonly found in the dissolved fraction. ${ }^{20,29}$ Actually, the partitioning of metallic elements in drainage waters is strongly influenced by the rainfall $\mathrm{pH}$, the nature and amount of solids present, the solubility and pavement residence time of the element. ${ }^{29}$ Therefore, it is believed that Curitiba produces its own distinctive mix of sediment-flakes from different sources, which could act as a potential cadmium sorbent.

The distribution between the dissolved and particulate phases can also be evaluated by the partition coefficients expressed as

$K_{\mathrm{D}}=\frac{c_{\mathrm{p}}}{c_{\mathrm{d}}}$

where $K_{\mathrm{D}}$ is the partition coefficient $\left(\mathrm{L} \mathrm{kg}^{-1}\right), c_{\mathrm{p}}$ represents the concentration of particulate metal $\left(\mathrm{mg} \mathrm{kg}^{-1}\right)$, and $c_{\mathrm{d}}$ is the metal concentration in the dissolved fraction $\left(\mu \mathrm{g} \mathrm{L}^{-1}\right)$. Figure 6 presents the calculated $K_{\mathrm{D}}$ as a function of TSS concentration for $\mathrm{Cu}, \mathrm{Pb}$, and $\mathrm{Cd}$ during the sampling period.

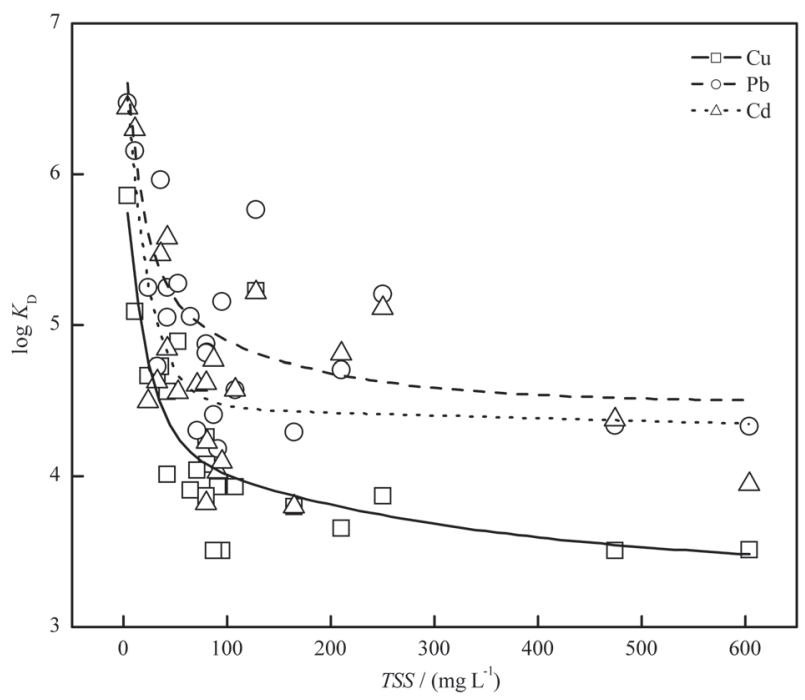

Figure 6. Copper, lead, and cadmium partition coefficients $\left(K_{\mathrm{D}} / \mathrm{L} \mathrm{kg}^{-1}\right)$ determined at different TSS concentrations in urban runoff waters.

Figure 6 portrays different behaviors among the metals present in urban runoff waters suggesting that $\mathrm{Pb}$ is the one most strongly bound to TSS, followed by $\mathrm{Cd}$ and $\mathrm{Cu}$. It is also possible to notice that $K_{\mathrm{D}}$ decreases with TSS concentration. In fact, similar results have been reported in previous works. ${ }^{37,38}$ Such behavior can be explained by the relative enrichment of metals in TSS at low particles concentrations, and relative depletion of metals in TSS at high solids concentrations. In addition, the presence of colloidal species induces the so-called "particle concentration effect". ${ }^{39}$ When TSS levels increase, the concentration of fine-sized colloids $(<0.45 \mu \mathrm{m})$ is also expected to increase due to the operational separation between the dissolved and particulate fractions. Such colloidal particles are able to bind metals and retain them in solution, hence increasing the concentration of dissolved metals. As a result, the $K_{\mathrm{D}}$ values obtained under high 
TSS concentrations are lower than those at low TSS concentrations. The presence of colloid-metal particles in runoff waters was also detailed by Marsalek and Marsalek, ${ }^{22}$ which reported greater metal concentrations in the downstream half of a stormwater management pond in Kingston (Canada) due to the presence of mobile forms such as fine-sized silt and clay.

In natural waters, the presence of dissolved metals is commonly reported as a consequence of their complexation by the dissolved organic matter. ${ }^{40,41}$ Although no complexation studies were carried out in this investigation we were able to examine the relationship between the presence of the three metals in the dissolved phase and the COD levels determined in runoff waters as it is shown in Figure 7.

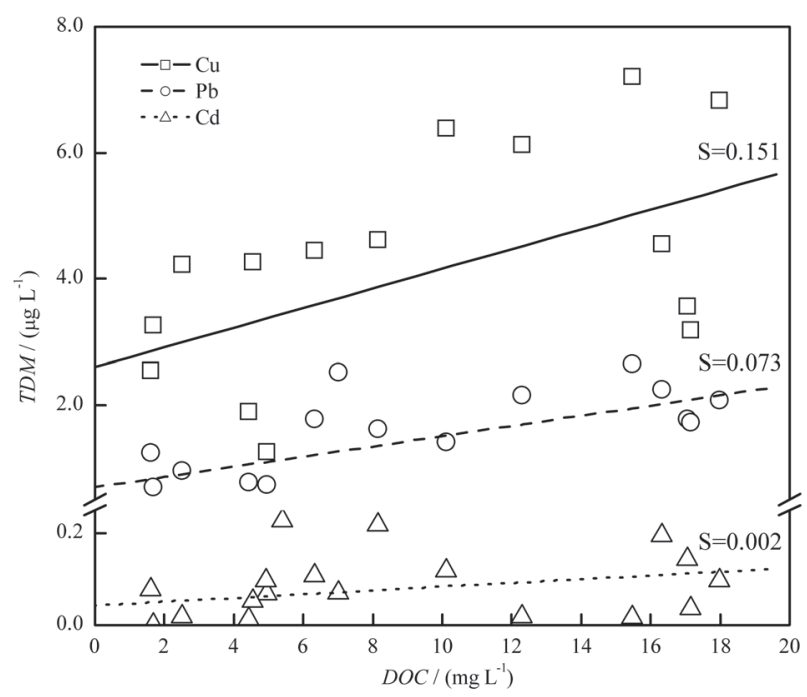

Figure 7. Total dissolved metal concentrations as a function of dissolved organic carbon levels in runoff waters.

From Figure 7 it is possible to observe a relationship between the concentration of metals in the dissolved phase and the DOC content in the drainage water. The slopes of the curves suggest a better correlation between $\mathrm{Cu}$ and DOC concentrations, followed by $\mathrm{Pb}$ and $\mathrm{Cd}$. We believe that the major presence of copper in the dissolved phase is a consequence of its greater binding affinity to the organic carbon in this phase. Actually, the presence of copper-complexes in surface runoff waters has been reported in the literature. ${ }^{41}$ Sedlak et al. ${ }^{42}$ detailed the presence of moderately strong metal-complexing ligands, which are responsible for the complexation of about 5$50 \%$ of the $\mathrm{Cu}$ in the dissolved phase. The existence of metal-complexing ligands in surface runoff waters must be accounted for when evaluating runoff management and treating practices.

\section{Conclusions}

The results obtained in this work confirm that urban stormwater runoff represents an important source of heavy metals to receiving surface waters. During the monitored period we collected information that revealed significant concentrations of lead, copper, and cadmium as well as considerable amounts of suspended solids in runoff waters. The loadings estimates of $\mathrm{Pb}, \mathrm{Cu}$, and $\mathrm{Cd}$ were compatible to previous works reported in the literature, despite the fact that pollutant loads are frequently broad due to the complexity of the contaminant sources. A first flush effect was observed during a storm event for particulate $\mathrm{Pb}$ and $\mathrm{Cd}$ as well as for dissolved $\mathrm{Cu}$. During the sampling period lead and cadmium were primarily particulate-bound whereas copper was mainly dissolved. The knowledge of metal partitioning is an important aspect for the management of urban stormwater runoff. High amounts of suspended solids and consequently particulate metals can be removed through some simple treatment techniques such as streets sweeping as well as through the employment of sustainable urban drainage systems (SUDS) such as wet detention ponds and filters. These practices would strongly reduce the loadings of metallic species that could reach natural waters. Finally, we consider that our findings provide reliable information concerning the necessity of public policies devoted to the protection of aquatic ecosystems.

\section{Acknowledgments}

The authors would like to thank Fundação Araucária de Apoio ao Desenvolvimento Científico e Tecnológico do Paraná and CNPq. FFS, VEA, and ECP also thank CAPES and CNPq for the fellowship. Finally, the authors are grateful to Instituto Tecnológico Simepar for providing precipitation data.

\section{References}

1. Fuchs, S.; Haritopoulou, T.; Schäfer, M; Wilhelmi, M.; Water Sci. Technol. 1997, 36, 277.

2. Gray, L.; Hydrobiol. 2004, 518, 33.

3. Mitchell, G.; J. Environ. Manage. 2005, 74, 1.

4. Bunce, N.; Environmental Chemistry, $2^{\text {nd }}$ ed., Wuerz Publishing Ltd.: Winnipeg, 1994.

5. Taebi, A.; Droste, R. L.; Sci. Total Environ. 2004, 327, 175.

6. Mota, S.; Urbanização \& Meio Ambiente. ABES: Rio de Janeiro, 1999.

7. Tucci, C. A. E. M.; Ciência \& Cultura 2003, 55, 36. 
8. http://www.epa.gov/owow/nps/facts/point1.htm, accessed in June 2005.

9. Sodré, F. F.; Anjos, V. E.; Prestes, E.C.; Grassi, M. T.; J. Environ. Monit. 2005, 7, 581.

10. Wu, J. S.; Holman, R. E.; Dorney, J. R.; J. Environ Eng. 1996, 122, 983.

11. Wu, J. S.; Allan, C. J.; Saunders, W. L.; Evett, J. B.; J. Environ. Eng. 1998, 124, 584.

12. Lee, J. H.; Bang, K. W.; Water Res. 2000, 34, 1773.

13. Boller, M.; Water Sci. Technol. 1997, 35, 77.

14. Davis, A. P.; Shokouhian, M.; Ni, S.; Chemosphere 2001, 44, 997.

15. Barret, M. E.; Irish Jr., L. B.; Malina Jr., J. F.; Charbeneau, R. J.; J. Environ Eng. 1998, 124, 131.

16. Boller, M.; Steiner, M.; Water Sci. Technol. 2002, 46, 173.

17. Chebbo, G.; Gromaire, M. C.; J. Hydrol. 2004, 299, 312.

18. Yuan, Y.; Hall, K.; Oldham, C.; Sci. Total Environ. 2001, 266, 299.

19. Färm, C.; Sci. Total Environ. 2002, 298, 17.

20. Sansalone, J. J.; Buchberger, S. G.; Water Sci. Technol. 1997, $36,155$.

21. Wiesner, M. R.; Characklis, G. W.; Brejchovà, D. In Metals in Surface Waters; Allen, H. E.; Garrison, A. W.; Lutther III, G. W., eds.; Ann Arbor Press: Chelsea, 1997, ch. 2.

22. Marsalek, J.; Marsalek, P. M.; Water Sci. Technol. 1997, 35, 117.

23. Sartor, J. D. D.; Boyd, G. B.; Water Pollution Aspects of Street Surface Contaminants, U.S. EPA: Washington, D.C., 1972.

24. Sartor, J. D. D.; Boyd, G. B.; Agardy, F. J.; J. Water Pollut. Control Fed. 1974, 46, 458.

25. U.S. EPA. Final Report of the Nationwide Urban Runoff Program, Water Planning Division: Washington, D.C., 1983.

26. Newell, C. J.; Rifai, H. S.; Bedient, P. B.; Characterization of Non-point Sources and Loadings to Galveston Bay. Galveston Bay National Estuary Program: Houston, 1992.
27. Goonetilleke, A.; Thomas, E.; Ginn, S.; Gilbert, D.; J. Environ. Manage. 2005, 74, 31.

28. Boller, M.; EAWAG News 2003, 57, 23.

29. Sansalone, J. J., Buchberger, S. G.; J. Environ. Eng. 1997, 123, 134.

30. Barbosa, A. E.; Hvited-Jacobsen, T.; Sci. Total Environ. 1999, 235, 151.

31. U.S.EPA; Sampling Ambient Water for Determination of Trace Metals at EPA Water Quality Criteria Level, Office of Science and Technology: Washington, DC, 1996.

32. Sodré, F. F.; Peralta-Zamora, P. G.; Grassi, M. T.; Quim. Nova 2004, 27, 695 .

33. Campos, M. L. A. M.; Bendo, A.; Viel, F.; Quim. Nova 2002, $25,808$.

34. APHA-AWWA-WPCF; Standard Methods for the Examination of Water and Wastewater, $19^{\text {th }}$ ed., American Public Health Association: Washington, 1995.

35. Legret, M.; Pagotto, C.; Sci. Total Environ. 1999, 235, 143.

36. Bris, F. J.; Garnaud, S.; Appery, N.; Gonzalez, A.; Mouchel, J. M.; Chebbo, G.; Thevenot, D.; Sci. Total Environ. 1999, 235, 211.

37. Grassi, M. T.; Shi, B.; Allen, H. E.; J. Braz. Chem. Soc. 2000 , $11,516$.

38. Lu, Y.; Allen, H. E.; Sci. Tot. Environ. 2001, 277, 119.

39. Benoit, G.; Oktay-Marshall, S. D.; Cantu II, A.; Hood, E. M.; Coleman, C. H.; Corapcioglu, M. O.; Santschi, P. H.; Mar. Chem. 1994, 45, 307.

40. Wells, M. L.; Kozelka, P. B.; Bruland, K. W.; Mar. Chem. 1998, 62, 203.

41. Jin, L.; Gogan, N. J.; Anal. Chim. Acta 2000, 412, 77.

42. Sedlak, D.; Phinney, J. T.; Bedsworth, W. W.; Environ. Sci. Technol. 1997, 31, 3010. 